\title{
NORMAS PARA A CIRCULAÇÃO DE TRABALHADORES NO MERCOSUL
}

\author{
Amauri Mascaro Nascimento \\ Professor Titular do Departamento de Direito do Trabalho \\ da Faculdade de Direito da Universidade de São Paulo
}

\begin{abstract}
Resumo:
O Mercosul veio trazer questões novas dentre as quais a necessidade de simplificar a circulação dos trabalhadores nos países que $o$ integram e a harmonização das leis nacionais para que, na medida do possível, o tratamento dispensado a essas situações venha a ser o quanto possível uniforme.
\end{abstract}

Abstract:

Mercosul has raised new issues such as the need of simplifying the worker's circulation among the associated countries and the national law's harmonization, in order to, whenever possible, unify the treatment given to these situations.

I. A situação atual de ingresso e permanência de trabalhadores no Brasil.

As normas destinadas a reger a circulação de trabalhadores no Brasil devem ser revistas em função do Mercosul, suas necessidades não-coincidentes com o quadro atual e os imperativos decorrentes da instituição de uma comunidade internacional.

Dentre os muitos aspectos que exigem uma nova regulamentação incluam-se, exemplificativamente, as novas categorias de ingresso de trabalhadores no País, condições de admissão, procedimentos e requisitos exigidos, prazos de permanência, proibições e causas de deportação, expulsão ou extradição, atividades permitidas ou proibidas, exigências formais para obter a permanência, programas de incentivo ao ingresso de imigrantes com capital, sanções para estrangeiros clandestinos, punições ao empregador que tiver a seu serviço um trabalhador clandestino, fronteiriços, transferências de pessoal pelas empresas com atividades em mais de um País, por tempo determinado e indeterminado, questões cuja remuneração revela a complexidade das medidas que devem ser definidas.

Não há definição legal, no Brasil, sobre migração trabalhista e as regras do direito interno estão previstas na legislação comum sobre Estatuto do 
Estrangeiro, salvo algumas resoluções administrativas. Desse modo, a movimentação de pessoas, para trabalhar ou para outros fins, é regulada através das normas aplicáveis ao estrangeiro em geral, cujas origens são antigas.

Numa síntese aproximada da evolução das leis, cite-se o Código Civil, de 1916, art. $3^{\circ}$, que declarou que "a lei não distingue entre nacionais $e$ estrangeiros quanto à aquisição e ao gozo dos direitos civis" O Decreto n. 18, de 11 de setembro de 1928, tornou obrigatório o passaporte, sob o impacto dos interesses da colonização e de restrições de exploração de minas e jazidas minerais. Por força do Decreto n. 18.926, de 1929 e do Decreto n. 18.871, do mesmo ano, foram incorporadas, ao Direito brasileiro, as diretrizes da "Convenção sobre a Condição Jurídica do Estrangeiro" de Havana, 1928, cujo art. 5, dispõe: "Os Estados devem conceder aos estrangeiros domiciliados ou de passagem em seu território todas as garantias individuais que, concedem aos próprios nacionais e o gozo dos direitos civis essenciais, sem prejuizo, no que concerne aos estrangeiros, das prescrições legais relativas à extensão e modalidades do exercício dos ditos direitos e garantias"; e as regras do Código de Direito Internacional Privado (Código Bustamante), cujo art. $1^{\circ}$ declara: "Os estrangeiros que pertençam a qualquer dos Estados contratantes gozam no território dos demais, dos mesmos direitos civis que se concedam aos nacionais"

Iniciou-se, em 1930, o desenvolvimento de uma política de proteção à mão-de-obra nacional implementada, através da legislação da União sobre imigração e trabalho do estrangeiro. A partir de 1942 valorizou-se um aspecto, a residência no País, independentemente da nacionalidade, como fator de integração do estrangeiro em nosso ordenamento jurídico.

A Constituição de 1967 e a Emenda constitucional de 1969 (art. 153) asseguraram aos estrangeiros isonomia com os brasileiros quanto à inviolabilidade dos direitos à vida, liberdade, segurança e propriedade com duas restrições previstas nos artigos $173,1^{\circ} \S$ e 174 , I e III e seu $\S 1^{\circ}$. A primeira refere-se aos comandantes de navios nacionais e a parte da tripulação - dois terços, pelo menos - desses navios, com reserva para brasileiros natos, regra que passa por modificações atuais. A segunda diz respeito à propriedade e administração de empresas jornalísticas de qualquer espécie, inclusive de televisão e de radiodifusão, vedada a estrangeiros e às sociedades que tenham, como acionistas ou sócios, estrangeiros, reservando-se a responsabilidade e a orientação intelectual e administrativa, das empresas mencionadas, a brasileiros natos. 
A Constituição Federal de 1988 e a Lei n. 6.815 , de 19 de agosto de 1980, o Estatuto do Estrangeiro, atualizada pela Lei n. 6.964, de 9 de dezembro de 1981, regulamentada pelo Decreto n. 86.715, de 10 de dezembro de 1981, introduziram novas disposições. Destaquem-se, ainda, a Lei n. 6.815 , de 19 de agosto de 1989 que define a situação jurídica do estrangeiro no Brasil e cria o Conselho Nacional de Imigração, regulamentada pelo Decreto n. 86.715, de 10 de dezembro de 1981; o Decreto-lei n. 691, de 18 de julho de 1969 sobre técnicos estrangeiros; e a Lei n. 7.064, de 6 de dezembro de 1982 e Decreto n. 89.339, de 31 de janeiro de 1984, sobre pessoal contratado ou transferido, na área da construção civil, para prestar serviços em outro país.

Observe-se que a Consolidação das Leis do Trabalho, no art. 352 e seguintes, estabelece reserva de mercado com a denominada lei dos dois terços ao instituir uma proporcionalidade de empregados brasileiros nas empresas nacionais, segundo um princípio de nacionalização do trabalho, cuja compatibilidade com a internacionalização resultante do Mercosul deve ser aferida.

Dentre os atos e normas expedidas pela Administração Pública incluam-se a Portaria do Ministério do Trabalho n. 3.721, de 31 de outubro de 1990, que baixa instruções para simplificação dos procedimentos da chamada de mão-deobra estrangeira; a Resolução do Conselho Nacional de Imigração n. 25, de 25 de março de 1994, que dispõe sobre concessão de visto permanente a estudantes estrangeiros admitidos para estágio no Brasil, mediante bolsas de estudo pagas por empresas ou instituições onde os mesmos realizarem os estágios; e a Resolução do Conselho Nacional de Imigração n. 26, dé 25 de março de 1994, que dispõe sobre a concessão de visto permanente ao pesquisador estrangeiro que pretender se fixar no País para exercer atividade junto a instituições de pesquisas em ciência e tecnologia.

Acrescente-se que o Brasil ratificou a Convenção n. 97, da Organização Internacional do Trabalho, sobre trabalhadores migrantes (Decreto $\mathrm{n}$. 58.819 , de 14 de julho de 1966), a Convenção $\mathrm{n}$. 19 sobre igualdade de tratamento entre estrangeiros e nacionais em acidentes de trabalho (Decreto n. 41.721, de 25 de junho de 1957), a Convenção $\mathrm{n} .118$ sobre igualdade de tratamento entre nacionais e estrangeiros em matéria de seguridade social (Decreto n. 66.497, de 27 de abril de 1970), o Tratado para o Estabelecimento de um Estatuto das Empresas Binacionais Brasileiro-Argentinas (Decreto-legislativo n. 28/92 e Decreto n. 619/92), o Protocolo adicional de Itaipu (Decreto n. 75.242, de 17 de janeiro de 1975), o Acordo de Previdência Social Brasil-Uruguai (Decreto n. 85.248, de 13 de outubro 
de 1980) e o Acordo de Previdência Social Brasil-Argentina (Decreto n. 87.918, de 7 de dezembro de 1982) e assinou a Declaração Internacional dos Direitos Humanos, o Pacto Internacional de Direitos Civis e Políticos, o Pacto Internacional de Direitos Econômicos, Sociais e Culturais, a Declaração Americana dos Direitos e Deveres do Homem, a Carta da Organização dos Estados Americanos e a Convenção Americana sobre Direitos Humanos (Protocolo de São José da Costa Rica).

II. A necessidade de revisão das leis.

Com o Mercosul são desenvolvidos estudos, através de diversas comissões, sobre as relações de trabalho no Brasil, Argentina, Uruguai e Paraguai abrangendo, também, as linhas gerais de uma proposta para a elaboração de um Protocolo entre os quatro países, com as diretrizes básicas a serem observadas quanto à circulação dos trabalhadores e que terá, certamente, reflexos sobre o nosso direito.

Essas repercussões atingirão, por exemplo, o Estatuto do Estrangeiro (Lei n. 6.815/80, art. $4^{\circ}$ ) que ao classificar as hipóteses de ingresso do estrangeiro no Brasil leva em conta os tipos de vistos, condicionando a prestação de serviços segundo esse ângulo não-trabalhista de classificação. Vale dizer que o trabalho é mera decorrência, mas não causa de ingresso no País, aspecto que não se coaduna com o Mercosul.

Com efeito, ao dispor sobre admissão, entrada ou impedimento de estrangeiro no País, o Estatuto do Estrangeiro prevê as seguintes hipóteses de concessão de visto que correspondem a uma classificação de ingressos: 1. trânsito para aquele que, para atingir o país de destino, tenha que entrar em território nacional; 2. turista para o estrangeiro que vier ao País em caráter recreativo ou em visita e que não tenha finalidade imigratória nem intuito de exercício de atividade remunerada; 3. temporário para o estrangeiro em viagem cultural, missão de estudos, viagem de negócios, artista, desportista, estudante, cientista, professor, técnico ou profissional de outra categoria sob regime de contrato ou a serviço do Governo brasileiro, jornalista de rádio, jornal, televisão ou agência estrangeira, ministro de confissão religiosa ou membro de instituto de vida consagrada e de congregação ou ordem religiosa; 4. permanente - ao estrangeiro: a) que pretenda se fixar no País, sendo que a imigração objetivará, primordialmente, propiciar mão-deobra especializada aos vários setores da economia nacional, visando a política 
nacional de desenvolvimento em todos os seus aspectos, principalmente ao aumento da produtividade, à assimilação da tecnologia e à captação de recursos para setores específicos; b) que pretenda se fixar no País como investidor com recursos de origem externa nas condições da Resolução n. 27/94 do Conselho Nacional de Imigração; c) pesquisador que pretenda se fixar no País para exercer atividades junto a instituições de pesquisas em ciências e tecnologia, na forma da Resolução n. 26/94 do Conselho Nacional de Imigração.

Completam a relação os vistos de cortesia, oficial e diplomático.

Cabe explicitar a situação do fronteiriço que é aquele situado defronte da fronteira do País. Ao natural de país limítrofe - fronteiriço -, domiciliado em cidade contígua ao território brasileiro, respeitados os interesses da segurança nacional, poder-se-á permitir a entrada nos municípios fronteiriços a seu respectivo país, desde que apresente prova de identidade (art. 21). Se pretender exercer atividade remunerada ou freqüentar estabelecimento de ensino nesses municípios, obterá documento especial e carteira de trabalho e previdência social (art. $21, \S 1^{\circ}$ ).

Quanto ao estudante estrangeiro, admitido em estágio no Brasil, é permitido o recebimento de bolsas de manutenção pagas pelas instituições ou empresas onde estagiar, nos termos da Resolução n. 25/94 do Conselho Nacional de Imigração.

Por outro lado, a Lei n. 6.815 , de 19 de agosto de 1980 , que criou o Conselho Nacional de Imigração, no art. $1^{\circ}$, declara que em tempo de paz, qualquer estrangeiro poderá, satisfeitas as condições previstas pela mesma lei, entrar e permanecer no Brasil e dele sair, resguardados os interesses nacionais e atendidas a segurança nacional, a organização institucional, os interesses políticos, sócioeconômicos e culturais do Brasil, bem assim as exigências da defesa do trabalhador nacional.

O resumo que acaba de ser feito é suficiente para mostrar que são inadequadas as diretrizes que foram estabelecidas, sendo de toda conveniência elaborar uma nova regulamentação para disciplinar a circulação dos trabalhadores no Mercosul.

III. Propostas para uma nova regulamentação.

A primeira questão que se coloca é sobre a conveniência ou não da normatização do tema no Mercosul e a resposta é afirmativa. Se o propósito que 
resulta do Tratado de Assunção é facilitar a migração trabalhista convém indicar as regras destinadas a fixar a estrutura de órgãos necessária para o desenvolvimento das metas previstas e as principais regras com base nas quais poderia ser promovida a referida circulação no território dos Países-membros.

A segunda questão é a forma pela qual as normas de migração no Mercosul devem ser implementadas. Parece-me que seria o caso de se propor um Protocolo entre os países, que permitirá a consubstanciação de um documento apto a atingir os seus fins.

Por outro lado, como foi explicado, as normas internas sobre ingresso de estrangeiros no território de um país precederam a criação do Mercosul e são inadequadas para dar respostas às novas situações que se formam decorrentes do fomento à circulação dos trabalhadores. Foram elaboradas tendo em vista as vicissitudes próprias ao ingresso do estrangeiro como tal e não do trabalhador estrangeiro, daí porque parte de critérios classificatórios que, se correspondem às exigências para as quais se destinam, não têm a mesma funcionalidade, quando se trata de examinar a circulação dos trabalhadores numa Comunidade Internacional. Assim, para dar atendimento às contingências da migração não devem ser classificadas as hipóteses permissivas de ingresso, levando em conta o tipo de visto que pode ser concedido ao estrangeiro na condição de turista, temporário ou permanente. Impõe-se, a partir das situações inerentes ao problema específico, elaborar outra classificação.

A tipologia de uma nova classificação poderia considerar:

a. as situações nas quais há migração em função das empresas para atendimento das necessidades de serviço, permanentes ou transitórias, em outro país;

b. as situações nas quais um trabalhador, por necessidade ou conveniência, toma a iniciativa individual de trabalhar em outro país, já contratado ou sem contrato, porque pretende se deslocar à procura de emprego;

c. o fronteiriço.

Acrescentaria a essas hipóteses fundamentais a situação do estrangeiro em viagem cultural, missão de estudos, viagem de negócios, artista, desportista, estudante, cientista, professor, técnico ou profissional de outra categoria sob regime de contrato ou a serviço do Governo brasileiro, jornalista de rádio, jornal, televisão ou agência estrangeira, ministro de confissão religiosa ou membro de instituto de vida consagrada e de congregação ou ordem religiosa e que deveriam ter um tratamento especial. 
No que se refere ao fronteiriço poder-se-ia permitir a sua entrada nos municípios limítrofes com o seu respectivo país, mediante apresentação de documento de identidade de natureza trabalhista. Seria possível, assim, a formalização do trabalho que presta e que, atualmente, é marginalizado e sem a proteção do ordenamento jurídico.

Não se concederia ingresso ao trabalhador: I menor de dezoito anos, desacompanhado do responsável legal ou sem a sua autorização expressa; II considerado nocivo à ordem pública ou aos interesses nacionais; III anteriormente expulso do país, salvo se a expulsão tiver sido revogada; IV - condenado ou processado em outro país por crime doloso passível de extradição; V - que não satisfaça as condições de saúde estabelecidas pelo Ministério da Saúde do país de ingresso. Essas disposições já são previstas pela nossa lei.

Seria viável a criação de um Conselho de Imigração do Mercosul com poderes para expedir resoluções destinadas a orientar e coordenar as atividades de imigração e para arbitrar questões migratórias.

Poder-se-ia prever a instituição de modelo único de cédula de identidade para o trabalhador migrante, a qual teria validade em todo o território do Mercosul, substituindo as carteiras de identidade ou outros documentos atualmente em vigor.

Dever-se-iam admitir proibições de livre circulação diante de determinadas situações e poderiam ser cogitadas as seguintes: a. cargos, empregos e funções públicas acessíveis aos nacionais; $b$. atividades consideradas contrárias ao interesse nacional; c. pesquisa e a lavra de recursos minerais, prospecção, exploração e aproveitamento das jazidas, minas e demais recursos minerais e dos potenciais de energia hidráulica, salvo autorização do Ministério a que estiver afeta a questão. Algumas dessas normas já são encontradas em nossa legislação.

Recomendar-se-ia a simplificação dos procedimentos de chamada de mão-de-obra estrangeira em caráter permanente ou temporário, solicitada por pessoa jurídica ou física e a uniformização dos procedimentos observados em cada país (formulários, autorização de trabalho, procuração com poderes para contratar mãode-obra, documento de arrecadação da Receita Federal, dados da empresa e do candidato, documentos da pessoa jurídica responsável pela chamada do estrangeiro, documentos do candidato, contrato de trabalho, trâmites dos documentos e órgãos pelos quais deverão tramitar, contrato social ou ato constitutivo da pessoa jurídica 
interessada, prova de regularidade da empresa perante a Receita Federal, o Instituto Nacional de Previdência Social).

Como se vê, o Mercosul suscitará novas questões jurídicas também no âmbito das relações de trabalho e que, por mais complexas que venham a ser, não devem desestimular os estudos daqueles que querem dar algum tipo de contribuição para que possam ser corretamente equacionadas. 